Nickson D, Price R, Baxter-Reid H \& Hurrell S, Skill requirements in retail work: the case of high-end fashion retailing, Work, Employment and Society (Volume 31, Issue 4) pp. 692-708. Copyright (C) The Authors 2016. Reprinted by permission of SAGE Publications.

\title{
Skill requirements in retail work: The case of high-end fashion retailing
}

Dennis Nickson

University of Strathclyde, UK

Robin Price

Queensland University of Technology, Australia

Hazel Baxter-Reid

Queen Margaret University, UK

Scott Hurrell

University of Glasgow, UK

Paper accepted for publication in Work, Employment and Society (accepted $26^{\text {th }}$ August 2016) 


\begin{abstract}
This article considers skill requirements in retail work, drawing on the example of high-end fashion retailing. It considers debates about the required 'soft' and 'hard' skills for such work. Drawing on Cockburn's (1983) typology of: skill residing in the worker; in what is required to perform a job; and as a socially constructed political concept, it seeks to offer more nuanced discussion of the nature of skills in retail work beyond the usual characterisation of such work as being inherently low skilled. Data is reported from 37 interviews with managers, supervisors and employees in a range of high-end fashion retailing outlets. The article recognises how this work was seen as skilled by the interviewees, particularly with regard to the desired product knowledge and selling ability required for such work. Lastly, it seeks to refine Cockburn's typology in understanding skill requirements in retail work.
\end{abstract}

Keywords: retail work; high-end fashion retailing; soft and hard skills 


\section{Corresponding author:}

Dennis Nickson, Department of Human Resource Management, Strathclyde Business School, University of Strathclyde, 199 Cathedral Street, Glasgow G4 OQU, UK. Email:

d.p.nickson@strath.ac.uk 


\section{Introduction}

This article seeks to engage with on-going debates about the nature of skill in interactive service work by considering skill requirements in high-end fashion retailing. Retail work is usually seen as undifferentiated and 'low skilled' (e.g. Bozkurt and Grugulis, 2011), but others have highlighted differences between the service offering in different sub-sectors or market segments (e.g. Mason and Osborne, 2008). In the specific context of fashion retail Pettinger (2004) suggests that the personal service required in some market segments may indeed possess recognisable elements of skill. There has, however, been little work to date that systematically examines the skills content of such work. Although a recent study posits the degradation of skill in retail department stores (Ikeler, 2015), we would argue Ikeler's study does not holistically address the skill content of these jobs, focussing primarily on emotional labour. For example, the manner in which product knowledge is subsumed under emotional labour by Ikeler neglects an alternative view of such work as being characteristic of harder, more traditional elements of skill in terms of having desired competence or knowledge (Lloyd and Payne, 2009). In addressing this gap, this article draws on Cockburn's (1983) work which articulates the multi-faceted dimension of skill: as residing in the worker themselves; in what is required to perform a job; and as a socially constructed political concept. The article therefore addresses a gap in engaging with calls for detailed, in-depth studies to highlight the potential diversity in the actual skill content of different front-line service jobs (Gatta et al, 2009; Korczynski, 2005). The article makes a particular contribution in demonstrating the complex nature of analysing the skills requirements of service work, refining Cockburn's typology as a result. 
The article begins by briefly considering the nature of retail work, highlighting the potential for variability within such work. The discussion then considers how skill may be conceptualised, outlining how Cockburn's typology may be applied to high-end fashion retailing. It is recognised that high-end fashion retail employees must have an appropriate mix of both soft and hard elements of skill. For example, having the required aesthetic and emotional labour (Hochschild, 1983; Nickson et al., 2001; 2005) to ensure the 'right' look and the ability to enact high quality customer service needs to co-exist with harder, technical elements, such as having and utilising extensive product knowledge. This mix of skills allows high-end fashion retailers to offer a more personalised service in which employees 'sell', not just serve (Pettinger, 2004). The article reports data from 37 interviews with managers, supervisors and employees in 15 fashion retail outlets. The results indicate that high-end fashion retail work contains recognisable elements of skill and that workers see themselves as distinct, constructing their work as being more skilled than other retail workers. These factors do not, however, mean that these jobs attract an appropriate level of reward for the skill level. The article concludes by considering the implications of these findings for views about the skills content of retail work.

\section{The nature of retail work}

Retail employment represents about 10 per cent of employment in most developed countries (ILO, 2015). Working in retail is generally perceived as a 'low skill' occupation, with low status, low pay and limited career opportunities (Bozkurt and Grugulis, 2011). We would, however, argue that this characterisation masks the variety of skills demanded by employers within the sector. This diversity can be seen in the many different sub-sectors in retail as well as different types of product market strategies, which in turn creates demand for workers with 
different skills. Mason and Osborne (2008), for example, note the electrical retailers they studied sought to employ people for front-line jobs with a pre-existing knowledge of electrical goods, further developing this product knowledge through on-going training once employed. This expectation of significant product knowledge was compared with food retailing, where product knowledge played little or no role in the job of front-line employees (ibid). In terms of product markets, Pettinger (2004) identified how the differentiation of retail fashion brands has an impact on the service offering, the skills and attributes demanded of the 'ideal' worker and, consequently, the labour processes they enact. She unpacks the definition of 'customer service' in fashion retail to identify three models - self-service, routine service and personal service. With self-service and routine service there is limited engagement with the customer, for example processing transactions at the till. Pettinger (2006) suggests that self-service is the dominant form of retail sales in fashion clothing stores, arguing that 'a great deal of the work done in retail outlets is aimed at enabling shoppers to serve themselves' (p. 58). Consequently, 'social interactions are not necessarily the dominant attribute of this form of work' (ibid:. p. 62). However, where a brand strategy demands more personal service, such as in high-end outlets, there are expectations that employees will enact a more personalised interaction with the customer, treading 'a delicate line between service and selling' (ibid: 174). The question arises as to how these different service models may be analysed via the lens of skill, which we do next, drawing on the work of Cockburn (1983).

\section{Conceptualising the skills requirements of retail jobs}


The concept of skill was traditionally concerned with how 'real' or hard technical and craft knowledge was applied (Vallas, 1990: 391). Discussions of skill have, however, extended into soft, social and interpersonal skills, which are central to interactive service work including retail (Gatta et al, 2009; Korczynski, 2005). Hurrell et al. (2013) define soft skills as, 'non-technical and not reliant on abstract reasoning, involving interpersonal and intrapersonal abilities to facilitate mastered performance in particular social contexts'. The use of such skills in service settings has been captured within concepts such as emotional and aesthetic labour (Hochschild, 1983; Warhurst and Nickson, 2007a). These respectively refer to employer commodification of employees' emotional and physical/corporeal displays to add value to service encounters and to represent the desired image of the organisation. Service employees are thus expected to behave and present themselves in a way consistent with the organisational context within which they work. There are critics who view discussions of soft skills within service work as devaluing the concept of skill due to these being simply personal, 'natural' attributes (see for example Lloyd and Payne, 2009). Others have, however, argued that work reliant on soft elements of skill can indeed be viewed as 'skilled' if systematically analysing such jobs through established skills typologies (Gatta et al., 2009; Hurrell et al., 2013; Korczynski, 2005). We thus analyse the skills requirements of retail work via the typology of Cockburn (1983) integrating soft and hard elements of skill within this discussion.

Cockburn (ibid: 113) presents a three-fold conceptualisation of skill. The first resides in the worker themselves, '....accumulated over time, with each new experience adding to a total ability', this perspective of skill thus reflects ability as acquired through learning, knowledge and increased mastery. The second is the skill demanded by the job, 'which may or may not match the skill of the worker', with the skill content of jobs determined by content of work 
tasks and the control that workers have over the labour process. The third is skill as a political process such that workers, 'can successfully defend against' threats to their status as skilled workers. This typology can be usefully elucidated upon and applied to interactive service work and the case of high-end fashion retailing.

When examining skill in the worker, differential requirements for contextual and product knowledge in service work raise the issue of the complementarity, or otherwise, between soft and hard elements of skill. Grugulis and Vincent (2009) highlight instances where soft skills may be seen as an alternative to harder, technical knowledge and expertise. However, these skills can co-exist and be used to differentiate service settings and skills requirements. Within the specific context of fashion retail, Pettinger's (2004) personal service necessitates employees' embodying the brand through highly developed aesthetic labour, the possession of selling skills and a high level of product knowledge. Consequently it could be argued that there is a degree of interdependence between the required soft and hard elements of skill, casting doubt on whether these are a dichotomy, hence the preference here to refer to these as soft and hard elements of skill rather than distinctive sets of skills in their own right. A combination of both elements of skill could contribute to the perception of high-end retail work as being skilled.

Sociological analysis is particularly concerned with locating skill in the job through focussing on work structures and job requirements (Vallas, 1990). Here the skills content of work is viewed through task complexity, autonomy and discretion (Green, 2011). Within the context of interactive service work, Korczynski (2005) sees job complexity as related to the simplicity/difficulty of a job with regard to tangible (e.g. operation of equipment) and 
intangible elements (e.g. aesthetic and emotional labour). He supports the idea that interactions with customers may vary in complexity and, as such, work which requires employees to diagnose and enact appropriate emotional labour can be skilled. Similarly, in considering task discretion, there is also scope within the original 'service offer' for employees to use discretion in selecting appropriate emotional labour and selling techniques. In retail, Ikeler (2015) differentiates between 'semi-skilled' and 'deskilled', department store environments, with the former involving higher task complexity and autonomy. The personalisation required in Pettinger's (2004) personal service would also be expected to coincide with a greater degree of complexity, autonomy and discretion, which could be seen as a distinctive and skilled kind of interactive service work.

When considering skill as a political concept, Vallas (1990: 390) notes that 'the labelling of certain jobs or occupations as "skilled" reflects a wide array of social and ideological processes quite apart from the demands of workers' tasks'. In a Weberian sense workers may socially construct their own job as skilled in order to secure social closure or status (ibid). Workers derive internal self-esteem and worth through a sense that they are doing skilled, meaningful and autonomous work (ibid). Workers may, therefore, be keen to highlight the relative worth and value of their employment. The political process of skill is also used to socially value certain work and decide who is suitable for it. Much research has been done on how skills are valued by gender (Green, 2011). Cockburn's male printers, for example, felt women incapable of traditional highly skilled typesetting tasks and railed against the 'degrading' feminisation of their profession allowed by computerisation. Others have argued that ethnicity and class, as well as gender, are used by employers to determine a 'skills fit', wherein particular groups of workers are deemed to suit particular kinds of jobs (Warhurst et al., 2016). The manner in which employers seek this fit is suggested to be particularly 
pronounced for 'cool', 'desirable' or 'fashionable' high-end retail brands, where an attempt is made to appeal to employees' identities as consumers, creating what Williams and Connell (2010: 354) describe as 'worker-consumers' (see also Besen-Cassino, 2014 and Gatta, 2011). These studies provide evidence of employers seeking a particular embodiment of skills fit and employing white, middle class students who are felt to have the desired soft skills for such brands. A concern, therefore, remains that in socially constructing skill, employers may be reinforcing class and racial privilege (Warhurst et al., 2016).

We argue then that the retail sector has significant variety with regard to the type of work, workers employed and the required elements of skill. More specifically, in fashion retail we argue, drawing on and extending the work of Gatta (2011), Pettinger (2004) and Williams and Connell (2010), that there are differences in price, service model and the type of employees deemed to best represent that model. With regard to price, we distinguished between cheap; affordable/mid-range; high-end and luxury. In terms of service model, there are differences between the high street (where there is some service if customers seek it, but little requirement for product knowledge - mirroring Pettinger's self- or routine service) and high-end, where there are raised expectations regarding quality of service, product knowledge and levels of employee discretion (mirroring Pettinger's personal service). This latter model may contain elements synonymous with skill. Employees in high-end fashion retail are expected to have soft elements of skill encompassing aesthetic and emotional labour (i.e. having the 'right' look, an appropriate personality and selling ability) as well as harder, technical elements of skill (i.e. having a high level of product knowledge). That is not to say that we can unproblematically and objectively analyse skill, as who is considered suitable for certain jobs, and the true nature of skill involved will be affected by managers' and workers' politicised social constructions. 


\section{Methods}

The focus for this research was on high-end fashion retailers in Glasgow and Edinburgh. Both cities are acknowledged as being important retail centres in the UK, with Glasgow second only to London based on comparison spend (Experian, 2016). We acknowledge that there is some debate about what demarcates high-end from high street, with no definitive classification on what constitutes these differing retail segments in terms of turnover, average product prices, differentials in wages paid to employees and so on. That said, we did attempt to clarify what denoted high-end from high street drawing on a range of literature. For example, Williams and Connell (2010: 350) suggest high-end retailers are those 'between the mass discounters and luxury market'. Similarly, Quinn et al. (2007) recognise the difference between general fashion clothing retailers typically located in city centres, offering a mid to low-priced retail offer and designer retailers who offer much higher-priced products.

To generate a sample, members of the research team went on a 'walk around' the main shopping areas in the city centre of Glasgow and Edinburgh, and assessed a variety of different stores in terms of the quality and pricing of goods and service level in order to determine whether they were high-end retailers. As our central concern was to examine employee skills, including selling ability and product knowledge, we explicitly looked for evidence of personal service as identified by Pettinger (2004). We then examined the retailers' websites to confirm that they identified as high-end. Ultimately, participants were recruited by visiting the store, speaking to the store manager and staff about the research project and inviting their participation. Fifteen brands in total participated in the research. All brands operated internationally and had an online presence. All sites, bar one which was 
operated under licence, were company-owned. Six of the brands were womenswear fashion stores, two were menswear and seven offered men's and women's clothing. In total 37 interviews were undertaken (18 managers, two supervisors and 17 employees). Store managers were aware of which employees were interviewed, though interviews were conducted away from managers.

The age of participants ranged from approximately 19-50, the gender ratio was 70:30 female to male and 60 per cent of participants were university educated, with nine of the front-line staff being graduates. All managers and supervisors and almost half of the employees worked full-time. Interviews lasted between 30-90 minutes and were recorded and transcribed. The data from the interviews was analysed using NVivo, with a coding framework developed from the interview schedule, which considered work history, attraction to the job and the firm, recruitment, skills and knowledge required, training and development opportunities, and performance management. For the purposes of this article the findings are structured around Cockburn's (1983) notion of skill in the worker; skill in the job; and skill as a socially constructed political concept. However, as the analysis progressed it became clear that it was not useful to separate skill in the worker from skill in the job. If a job allows skill in the worker to accumulate over time via knowledge, experience and mastery (as Cockburn suggests), the requirements of the job then become embedded in the skills of worker. For this reason the findings for these two dimensions of skill are structured to reflect elements of skill in the worker which they brought to the job and elements of skill developed and utilised on the job itself.

\section{Elements of skill in the worker brought to the job}


In evaluations of skill in the worker, a series of proxies - such as educational qualifications and prior work experience - usually operate to distinguish skill levels between workers. However, high-end fashion retail, like the rest of the retail industry, does not require educational qualifications at the point of entry to the industry (Gatta, 2011; Nickson et al., 2012; Williams and Connell, 2010). That said, with the exception of some of the older interviewees, the majority were university educated or were current students.

The selection criteria for suitable skills were position dependent too. For entry level part-time sales positions, 'personality' and fit with the team; awareness of, and fit with, the brand; and availability to work were more important than prior experience. Employers thus sought soft and hard elements of skill alongside pragmatic considerations, such as availability. For fulltime roles retail experience was preferred, and for management roles, required. For high-end retailers, 'brand fit' was knowledge of, and identification with, the brand which translated as an appreciation for 'quality' products and seems to mirror Williams and Connell's (2010) notion of 'worker-consumers'. Some respondents reported knowledge of fashion that existed independently of their employment. As one supervisor noted:

You'll find that most of us will know about the [hand] bags that are coming out before they've told us in store, because we follow blogs [...] There's things like Purse Forum, so we'll know what customers are saying, and what they're going to come into us with [...] We're all bag geeks to be perfectly honest!

Our research highlighted that 'fit' was also about having appropriate personal attributes with regard to the required aesthetic labour and 'right' look to work in high-end fashion retail. In fashionable youth focused brands, the look was equated with being good looking, "without 
sounding pretentious and arrogant [...] you need to look good. [...] You wouldn't give somebody who was not good looking a job', suggested one employee. Usually though, there was less stress on being good looking, but instead on being 'always well-presented' (employee) and appropriately reflecting and embodying the brand, which could be considered as a skill informed by contextual knowledge rather than simply personal attributes (Pettinger, 2004). With regard to emotional labour, all interviewees articulated the importance of personality as a key attribute to work in high-end retail, 'if you have the right people, with the right personality, the right attitude and the right interpersonal skills they will sell', opined one manager.

\section{Elements of skill in the worker developed and utilised through the job}

Our findings highlight that a fundamental skill demanded by the job in high-end retail was the ability to sell expensive products. In order to ensure that employees were able to meet the demands of the job most organisations prescribed practical sales skills. All stores had a sales process and employees in each store recited a series of steps of selling, known by a range of titles and acronyms. One store had the 'five point plan', another 'six degrees of selling' whilst another structured the service encounter around the idea of 'GOTFAT - greet, observe, talk, fit, assist and thank'. One store manager explained this process as, 'very much the journey of the customer [...] staying with them throughout and then finishing the sale [...] someone could be with a customer from anything from 20 minutes or up to three hours'.

All of the retail staff interviewed discussed the need to 'read' customers as a tacit skill. The ability to read people resulted in employees adapting the sales process to suit the customer: 
I think you can learn selling skills but whether you're a people person or not you have to have that [ability to read the customer], because every customer that walks through the door is giving you opportunity [...] so you need to [...] know exactly what they're wanting. (Employee).

Reading customers was achieved by observing body language to ascertain the level of service required. It was apparent that as part of 'reading' customers, interviewees spent considerable time 'judging people, observing people.' (Employee), although it was suggested that this did not mean that all sales people were judgemental or that they stereotyped customers.

\section{Product knowledge}

In order to meet customer needs and the skills demanded by the job, namely to sell high priced goods, it was essential that employees had significant levels of product knowledge. A number of the interviewees considered their previous retail work experience in high street stores and agreed that significantly more product knowledge was required to work for a highend retailer. This was centred upon detailed knowledge of the features and benefits of products. Often the range of information required was extensive, with one store supervisor recognising that, 'we need to know the names of our garments basically. What they're made of, how you wash them, if it's dry clean and all of that. Even where the material's come from, where their source is from'. This need for knowledge extended across all employees and was viewed, according to one store manager, as 'just as important for a six hour person as a 40 hour person to know, because you don't know who's going to be serving who'. 
In some stores the variety of products stocked was diverse and related directly to the amount of knowledge that employees were required to have and to be able to recall. An employee noted how style name denoted a different fit on the customer, so as a consequence, 'you need to know them off by heart' so it was common for staff to try stock on to provide better recommendations for customers with different body shapes.' (Manager). Product knowledge needed continual updating as even stores that did not stock a large number of items held a range of collections (or 'stories') delivered across a given season. It was not just the product, its fit and which collection it belonged to, but what was described in one store as the 'c's': care, cost, composition and colour. Each store had its own version of the c's and knowledge of these was part of justifying the cost of expensive products to customers and being 'able to say why they are expensive and what the differences are from high street shops.' (Employee). When explaining the difference between a $£ 70$ and $£ 150$ shirt, one employee provided an example of using product knowledge to explain price difference and in the process reframe the customer's understanding:

... it's the structure of the shirt, the way it's been stitched together. It's still a very beautiful shirt but it's just simply constructed [...] it's the way you word things [...] you can't say 'well, that one's not constructed as well as that', it's just more simply constructed.

Moreover, one manager highlighted the customer's level of product knowledge: 'our customers are very discerning. They $[\ldots]$ are very, very knowledgeable about $[\ldots]$ the silk that their ties are made from'. Customers in these environments do not hesitate to let staff know their expectations either: 
My second day, a customer had got a really high priced bag and I didn't know anything about it. She actually commented on that to one of the [other] sales assistants that I was actually inadequate, those were her words. (Employee).

While employees felt that possessing a high level of product knowledge was a fundamental customer' expectation, some employees stressed how product knowledge was an important method of strengthening their selling technique: 'it's the knowledge of the product that pushes the sale', noted one employee. This was explained as highlighting a product's features and benefits to convince customers who were unsure about purchasing a product:

We don't expect people to know every single thing about every single item because that would be too much, but as long as they can drop into conversation a little chunk of knowledge [...] I think it makes it more genuine [...] It just makes the client think, 'oh, right, well that's why it's so expensive' and they might buy it. (Manager).

Furthermore, many organisations expected employees to follow recent fashion trends and be aware of what was happening in the wider fashion market, to increase their knowledge of products and the sector. Employers facilitated this interest in the workplace by providing fashion magazines and brand 'mood boards' in the staff room.

Styling skills

Employees could apply their knowledge of products, and utilise their selling skills when styling their customers. Styling customers was a significant demand of the job in many stores, and employees were given significant discretion and autonomy to suggest an appropriate 
style to their customers: 'when somebody's employed here, they're not called sales assistants, they're called style advisers [...] [as] a lot of [customers] know what they want but you might get somebody who'll come in and they're totally clueless.' (Manager). This process of styling extended to building the customer's individual confidence, trying to understand their needs and translate these into an outfit:

What they [the customer] say is they want to know what they're going to feel like when they're wearing this item, and you need to understand what feeling they want. If they want to look smart, you would bring them certain things, and if they want to look elegant you would get them other things [...] So we have the W questions. What do you want it for? Where are you going to wear it? When is it? What time of the day is it? What do you expect out of this event?

Employees were encouraged to be honest with customers about the products that customers were buying. In many stores, this honesty when styling was valued over 'trying to get a sale'. According to one manager this honesty would also extend to politely and subtly informing customers if a product was considered inappropriate. In all stores, interviewees suggested that selling a product that did not genuinely suit the customer, would result in negative advertising for the store and the possible loss of repeat custom.

However, three out of the fourteen stores paid individual employees commission and it was obvious that getting sales was very important, as one employee explained: 'Everything here is target driven, so if you don't have selling skills you're not going to meet your targets and that's not really going to end up working out'. Managers in these stores agreed that it was important the employees were self-motivated and had the desire to sell: 'I think they've 
[successful employees] got a competitive edge. They're hungry to achieve, hungry to sell [...] they've got a real willingness to want to help people and probably just got a good work ethic as well'. It was evident that obtaining sales and meeting targets were deemed more important in these commission paying stores.

\section{Training and Development}

In order to ensure that the skill that resides in the employee matched the skills demanded by the job, the majority of retailers offered extensive training and development. Training focused predominantly on product knowledge, selling skills and styling customers. After an induction and trial period, where they were gradually provided with information about procedural issues, product knowledge and selling skills, employees were expected to be proficient in their job: 'they have a trial period where we would train them in all the aspects of the shirts and products [...] after about 13 weeks they should be an expert in the product.' (Manager).

In relation to on-going training, this varied across the brands with some offering off-the-job training, while others delivered on-the-job training. In terms of off-the-job training, four brands sent employees to head office or the factory to introduce them to the brand and its manufacturing standards. This was reported by management and employees' as something that they felt was, according to one employee, 'amazing', such that the store, 'takes the time out to send a six hour person, to somebody that works for 40 hours. It's a massive expense, but they really believe in that'. The practice clearly provided rewards for the organisation though and one supervisor highlighted how it made employees feel 'involved and wanted'. 
On-the-job training was continual and occurred daily or regularly each week or month. Reflecting on this point one employee noted, 'I haven't experienced this in any other retailer before'. In each organisation, the main focus of training was on achieving sales and providing high levels of customer service, and in-depth knowledge of the product facilitated this aim. It was clear that training in some stores was comprehensive and encouraged employees to understand how the garments were made:

It doesn't tell you, this is silk, it's so expensive because it comes from worms, it tells you why. Everything's a why, or everything's a what. I could tell you exactly [...] what parts of Italy our suits come from, because it's made in family-owned mills that only provides us with our fabrics, so little things like that. (Manager).

However, at the other extreme, an assistant manager in a franchised Edinburgh retailer identified that training was 'few and far between, [head office representatives] come in here and do training like once every two years or something'. At the Glasgow company-operated branch of the same retailer the training experience was different, "we go to head office and they do denim campus training', so franchise status clearly makes a difference in the quality of the training provided.

Much of the responsibility for training employees fell on store management and it was apparent that some managers were much more diligent at developing their people than others. Some companies had an 'online training course, a series of modules' that provides 'case studies, it offers advice in terms of how to sell a suit'. More common, according to managers, was the use of a 'workbook', 'work sheets, manuals', 'glossary' or 'folders that the company provides' and the manager was tasked with guiding the employees through. Some form of 
homework was also common, such as a reflective journal so 'they record all their evidence so they can demonstrate their understanding of it.' (Manager), although as this employee noted, homework was couched in more appealing language as 'take-aways'. Although this practice was largely accepted by employees, it was still unpaid work that people were expected to do in their own time, therefore shifting the burden of training onto employees.

A common training method employed in a number of stores was role play, which developed employees' product knowledge, styling and selling skills. Numerous managers discussed how they proposed different scenarios and asked employees to sell items of clothing to different types of customers, 'we do games, like outfit building. We'll say [...] "Elaine's going on a date tonight".' (Supervisor). This approach was beneficial because it allowed for the sharing of ideas between staff.

It was clear that in these high-end stores employees were trained to take on extra tasks and responsibilities, such as visual merchandising or managing an area. It was not clear if interviewees were given extra pay, though some spoke about opportunities for advancement. The knowledge and skills required of employees in high-end fashion retailers can be summarised as: selling, product knowledge and styling ability. The skills in the person, innate and acquired, are therefore further developed by these retailers by means of fairly extensive off- and on-job training and development activities.

\section{Skill as a political concept}

The interviewees' perspective was that high-end fashion retail was both objectively and subjectively better than working in other mass market, high street fashion or general retailers. 
While a small number of interviewees had accidently fallen into their job, the majority had made a conscious decision to pursue a high-end position, often moving from mass market, high street brands. Reasons given for preferring high-end stores included: the nature of the customers, the work itself, colleagues and the work environment, free clothing and discounts (in most stores this was usually $50 \%$ and in one store went up to $75 \%$ ), job security, training and development provided and the travel and promotional prospects that derive from working for a large international chain.

The stores had very low levels of staff turnover, and several interviewees mentioned the long tenure of employees in the store, 'I've been here sixteen years, part of the furniture. One of my part-timers she's been here seven years. The only time that people generally leave is if they're students [...] then they qualify and they go on to get a full-time job.' (Manager). Another manager said, 'turnover is mainly for full-time staff who've been promoted'. There was a shared sense amongst interviewees that their employer was 'a really good company to work for' (employee) and that compared to their previous employers 'just far more interested in the people that work for them.' (Manager). The long tenure may reflect good working conditions, although only one interviewee specifically mentioned 'the salary and the benefits that it gives me.' (manager) as a benefit.

The nature of a high-end retail environment was subjectively perceived to have its own implicit rewards. For example, mirroring Besen-Cassino (2014) and Williams and Connell (2010), there was often a strong identification and affinity with the products and brand. One supervisor noted that: 
When we're having a bad day at home you can come into work and it's a bit of escapism for you as well. What a nice place to work, with beautiful handbags and beautiful clothes!' Maybe we can't afford to have these things, but when we come to work, they're our bags and it's our shop, it's our luxury.

Interviewees in other stores also talked about the importance of the quality of the products and the feeling that these would allow them to feel more honest with customers and sit better with their own ethical position, 'when I've worked in retail before, I've worked in places and the stock hasn't been great. The quality hasn't been great and I always felt like I was lying to customers when I was selling to them.' (Employee). The opportunity to build relationships with customers was also perceived to be a positive, expressed by a range of employees as being 'customer care based', being 'more intimate with a customer', and 'treating people with a lot of care and kindness'. High-end retail work was perceived as being 'more involved than just sort of putting stuff through the till.' (Employee). Interviewees thus sought to identify distinctive elements of working in high-end stores which could be seen to require a higher level of skill than work in mass market stores. As one store manager noted in terms of the difference between the price sensitive high street and higher priced high-end brands:

It's not a customer, it's a client. There's no service in the high street, it's stack it high, watch it fly. There's no standards in the high street, it's all about getting as many units through as possible in the quickest time possible, and then fill it up again, and the sales staff are just replenishment staff now. 
The description offered here by interviewees about the distinctiveness of high-end retail reflects Pettinger's $(2004 ; 2006)$ view of such work as being more about selling rather than simply serving.

\section{Discussion}

By unpacking the range of skills required to perform sales work in high-end retail, this article has taken up the call by Gatta et al. (2009) and Korczynski (2005) for detailed, in-depth studies of service workplaces to highlight the potential diversity in the actual skill content of different front-line service jobs. It has, thus, re-considered the assumption that jobs in retail are low-skilled, 'downtrodden, thankless and rather hopeless' (Bozkurt and Grugulis, 2011: 1). In focussing upon the degree of skill evident in the high-end fashion retailing labour process we would argue that this type of work may require a higher degree of skill and knowledge than lower-end fashion retailers, in part because of what is required to make a sale and enact the desired service in this setting. In doing so we have reinforced the complex nature of analysing the skills requirements of work, refining Cockburn's typology and also questioning the distinction between soft and hard skills.

Managers were clearly looking for knowledgeable employees who could then apply this knowledge in a way that was suitable for the particular customer they were dealing with, in a manner consistent with Pettinger's (2004) notion of personal service. That is not to say that all the characteristics sought were necessarily consistent with high skill. Some employers demanded attributes such as physical attractiveness, although contextualised and stylised selfpresentation were generally more important, reflecting the desired aesthetic labour for highend fashion retailers (Gatta, 2011; Pettinger, 2004; Warhurst and Nickson, 2007a). The 
consumption of style that enabled employees to gain some of the necessary product knowledge may be associated with middle classness and affluence, contributing to the idea of a labour aristocracy in high-end retail settings (Warhurst and Nickson, 2007b). Indeed, the majority of interviewees, including front-line sales staff, were university educated, generally in a creative (e.g. photography and fashion) or business field, and such qualifications could be viewed as a proxy for middle classness, potentially reinforcing class advantage (Warhurst et al., 2016). Employer demand for the desired soft skills reported here could be seen as companies capitalising on class privileged students and graduates, as in other high-end retail settings (Besen-Cassino, 2014; Gatta, 2011). As Warhurst et al. (2016) note, employers in services are concerned to seek a 'skills fit' which means that particular groups of workers are deemed as suited to particular kinds of service work. For the 'desirable' high-end retail outlets we studied, our findings are similar to work by Besen-Cassino (2014) and Williams and Connell (2010) of employees seemingly having a dual identity as 'worker-consumers' (cf. Misra and Walters, 2016). Furthermore, in the manner that soft skills are sought at the point of entry in high-end service settings, there remain concerns about how this process may limit employment to those of certain backgrounds, such as those who are deemed to have appropriate aesthetic labour and the 'right' look, the innate confidence and personality required for the desired emotional labour and be university educated (Nickson et al., 2003; Warhurst et al., 2016; Williams and Connell, 2010).

Although all of the companies that we considered had some prescriptions towards enacting the desired service encounter, such as the GOTFAT approach described in the findings, we contend that there was also evidence within the 'service offer' of a relatively high degree of job complexity, autonomy and discretion as noted by Korczynski (2005). Our evidence supports the contention that high-end fashion retail employees were expected to utilise a high 
degree of emotional labour in selling in a high-end environment (cf. Ikeler, 2015). Thus there was evidence of employees utilising selling skills (and having the appropriate personality to enact these) as well as the importance of reading customers. Additionally, though there was extensive evidence of how employees utilised product knowledge in high-end fashion retailing, their work goes beyond making sales to applying product knowledge to help customers make style choices. In some instances this placed staff in difficult positions where they may have to display tact and delicacy to suggest alternative choices to customers. These selling requirements thus needed a high degree of contextual skill. Following the typology of Hurrell et al. (2013) where higher skilled jobs, even those reliant on soft skills, can be characterised by increased demands for contextual knowledge - Cockburn's skill in the job under conditions of managerially facilitated discretion, the jobs represented here can be seen to contain elements of skill. Such skill existed despite employers using acronyms, manuals and steps to aid customer service. Indeed, there may be a case that the substantive and seemingly substantial product knowledge required by our interviewees goes someway to satisfying Lloyd and Payne's (2009: 631) more traditional concept of skills having 'a clear link to technical competence and knowledge'.

In analysing the above we conclude that these jobs contain recognisable elements of skill which, in turn, accrue to the worker via experience, practice and mastery - Cockburn's skill in the worker concept. In jobs which allow skill to be developed and utilised it is, therefore, incorrect to separate skill in the worker from skill in the job. It is instead more appropriate to consider skill brought to the job by the worker versus skill residing in the worker as developed and utilised by the job. We thus provide a refinement of Cockburn's typology, not seen in the work of others (see for example Ikeler, 2015 and Warhurst et al., 2016). Cockburn's study was set in the context of the deskilling of printing where new work 
practices did not allow workers to use their extant skills on the job. Her separation of skill in the worker and job may be more appropriately used within such a context, with our refinement used in jobs that $d o$ allow skills to be used.

The above analysis also casts doubt on whether soft and hard skills should be analysed distinctively. We view the overall skill level of a job as determined by various elements, residing in the worker, developed and enabled by the job. This overall level of skill can include both soft elements (here epitomised by the use of emotional and aesthetic labour) and hard elements (here epitomised by the need for extensive product knowledge). By viewing such elements holistically, we can better understand the nature of specific kinds of work.

Despite the recognisable elements of skill noted above, we also recognised Cockburn's concept of a skill as a political concept, whereby workers may seek to socially construct their own job as skilled in order to secure social closure or status (Vallas, 1990). Interviewees believed that their work was distinct from work in high street retailers, although many had experienced both kinds of work and thus may have made sound objective comparisons. This distinctiveness was reinforced by the degree of training received by the majority of these workers, which was seen as more comprehensive than training in lower-end retail employers. Despite individuals perceiving their work as being higher skilled and of better status than other retail work there is still an argument that the jobs remain objectively low quality (Warhurst et al., 2016). For example, and notwithstanding the suggestions from a minority of our interviewees that they were well rewarded, pay more generally in the retail sector is low (Mason and Osbourne, 2008) and more specifically data from the Office of National Statistics (ONS) suggests that pay in the clothing sub-sector, investigated here, is lower than other subsectors such as food retail, which encompasses supermarkets (IDS, 2015). It was also evident 
that employers expected employees to undertake training homework outside working time and without pay, thus extracting unpaid effort from workers. That positive subjective perceptions of work coincide with elements of low objective job quality is a contradiction that has been noted previously when analysing job satisfaction (Brown et al., 2012); a finding we extend into the sphere of skill.

\section{Conclusion}

This article has presented evidence that high-end fashion retail contains recognisable elements of skill and is viewed by both managers and employees as skilled work. In doing so it has furthered our understanding of retail work; provided in-depth analysis of the complexities involved in analysing the skill content of service work; and refined a widelyused typology of skills. The elements of skill we uncover appear to exist independently of workers' constructions. This is despite acknowledging that some workers' accounts may have emphasised their distinctiveness from other retail workers as a political tool to enhance their sense of status and self-worth. We would argue that high-end fashion retail should be seen as more skilled than retail work which does not possess the characteristics we have outlined. We thus concur with Ikeler (2015) who, despite noting an overall process of deskilling in retail, recognised distinctions between different types of retailers offering 'deskilled' and semiskilled' selling. Contra to Ikeler, however, we would contend that the degree of skill in such work goes beyond emotional labour into harder elements of skill, namely product knowledge. As both Ikeler (2015) and Mason and Osbourne (2008) respectively note, there may be scope for more skilled work in retail where products are 'niche' or 'specialised' and personal service provided. We would suggest that high-end fashion retail is an example of such work, though would also acknowledge the on-going debate about the extent to which this more 
skilled work is fairly rewarded and in particular whether the relative value ascribed to 'feminine' soft skills continue to be undervalued (Gatta et al., 2009; Korczynski, 2005). 


\section{Acknowledgements}

We would like to thank Professor Melanie Simms and the three anonymous reviewers for their extremely helpful comments on previous drafts of this article.

\section{Funding}

The authors received no financial support for the research, authorship and/or publication of this article

\section{References}

Besen-Cassino Y (2014) Consuming Work: Youth Labor in America. Philadelphia: Temple University Press.

Bozkurt O and Grugulis I (2011) Why retail demands a closer look. In: Grugulis I and Bozkurt O (eds) Retail Work. Basingstoke: Palgrave MacMillan, 1-24.

Brown A, Charlwood A and Spencer DA (2012) Not all that it might seem: why job satisfaction is worth studying despite it being a poor summary measure of job quality. Work, Employment and Society 26(6): 1007-1018.

Cockburn C (1983) Brothers: Male Dominance and Technological Change. London: The Pluto Press, New Edition. 
Experian (2016) Experian identifies which UK retail centres are best placed to survive and thrive. Available at http://www.experian.co.uk/marketing-services/news-retailscape-uk-retailcentres-best-placed-to-thrive.html

Gatta M (2011) In the 'blink' of an eye - American high-end small retail businesses and the public workforce system. In: Grugulis I and Bozkurt I (eds) Retail Work. Basingstoke: Palgrave MacMillan, 49-67.

Gatta M, Boushey H and Appelbaum E (2009) High-touch and here-to-stay: future skills demands in US low wage service occupations. Sociology 43(5): 968-989.

Green F (2011). What is Skill? An Inter-Disciplinary Synthesis, London: LLAKES Centre, Institute of Education, University of London.

Grugulis I and Vincent S (2009) Whose skill is it anyway? 'Soft' skills and polarization. Work, Employment and Society 23(4): 597-615.

Hochschild A (1983) The Managed Heart. Berkeley: University of California Press.

Hurrell S, Scholarios D and Thompson P (2013) More than a 'humpty dumpty' term: strengthening the conceptualization of soft skills. Economic and Industrial Democracy 34(1): $161-182$

Ikeler P (2015) Deskilling emotional labour: evidence from departmental store retail. Work, Employment and Society, published online ahead of print. 
Income Data Services (2015) 'Pay and conditions in retail', February.

International Labour Organization (2015) Employment Relationships in Retail Commerce and Their Impact on Decent Work and Competitiveness, available at: http://www.ilo.org/wcmsp5/groups/public/---ed_dialogue/--sector/documents/publication/wcms_351453.pdf

Korczynski M (2005) Skills in service work: an overview. Human Resource Management Journal 15(2): 3-14.

Lloyd C and Payne J (2009) 'Full of sound and fury, signifying nothing': interrogating new skill concepts in service work - the view from two UK call centres. Work, Employment and Society 23(4): 617-634.

Mason J and Osborne M (2008) Business strategies, work organisation and low pay in United Kingdom retail. In: Lloyd C, Mason G, and Mayhew K (eds) Low Wage Work in the United Kingdom. New York: Russell Sage Foundation, 131-168.

Misra J and Walters K (2016) All fun and cool clothes? Youth workers' consumer identity in clothing retail. Work and Occupations 43(3): 294-325.

Nickson D, Warhurst C, Commander J, Hurrell S and Cullen A M (2012) Soft skills and employability: evidence from UK Retail. Economic and Industrial Democracy 33(1) 62-81. 
Nickson D, Warhurst C, Cullen A M and Watt A (2003) Bringing in the excluded? Aesthetic labour, skills and training in the new economy. Journal of Education and Work 16(2): 185203.

Nickson D, Warhurst C and Dutton E (2005) The importance of attitude and appearance in the service encounter in retail and hospitality. Managing Service Quality 15(2): 195-208.

Nickson D, Warhurst C, Witz A and Cullen A M (2001) The importance of being aesthetic: Work, employment and service Organization. In: Sturdy A, Grugulis I and Wilmott H (eds) Customer Service. Basingstoke: Palgrave.

Pettinger L (2004) Brand culture and branded workers: service work and aesthetic labour in fashion retail. Consumption, Market and Culture 7(2): 165-184.

Pettinger L (2006) On the materiality of service work. The Sociological Review 54(1): 48-65.

Quinn L, Hines T and Bennison D (2007) Making sense of market segmentation: a fashion retailing case. European Journal of Marketing 41(5/6): 439-465.

Vallas SP (1990) The concept of skill: a critical review, Work and Occupations, 17(4): 379398.

Warhurst C and Nickson D (2007a) Employee experience of aesthetic labour in retail and hospitality. Work, Employment and Society 21(1): 103-120. 
Warhurst C and Nickson D (2007b) A new labour aristocracy? Aesthetic labour and routine interactive service. Work, Employment and Society 21(4): 785-798.

Warhurst C, Tilly C and Gatta M (2016) A new social construction of skill. In: Buchanan J, Finegold D, Mayhew K and Warhurst C (eds) Oxford Handbook of Skills and Training. Oxford: Oxford University Press.

Williams C and Connell C (2010) 'Looking good and sounding right': aesthetic labour and social inequality in the retail industry. Work and Occupations 37(3): 349-377. 
Dennis Nickson is Professor of Service Work and Employment at the Department of HRM, University of Strathclyde. His primary research interests centre on work and employment issues in interactive service work. He is one of the team - along with Professor Chris Warhurst and the late Professor Anne Witz - who developed the concept of aesthetic labour. His work has been published in journals such as Work, Employment and Society, Human Resource Management (US), the Human Resource Management Journal, the International Journal of Human Resource Management, and Economic and Industrial Democracy. He is also Editor-in-Chief of Employee Relations.

Robin Price is senior lecturer in the Queensland University of Technology Business School Management. Prior to joining academia, Robin worked in a variety of retail management and learning and development roles across the private and public sector. She researches and publishes on retail and service sector employment and trade unions in the service sector. Recently, she researched young people and their experiences of work, resulting in an edited book on Young People and Work (2011) with Ashgate. She is currently investigating pay equity in the public sector and young Indigenous people and their transitions into employment.

Hazel Baxter-Reid is a Lecturer in Human Resource Management at Queen Margaret University in Edinburgh. She completed her $\mathrm{PhD}$ in 2013, which examines the employment relationship of Central and Eastern European migrant workers in the UK. Her research interests lie in labour migration, and work and employment issues in low wage-work. 
Scott A Hurrell is Senior Lecturer in HRM and Organisational Behaviour in the Adam Smith Business School, University of Glasgow. His research interests include skills and work organization; labour market issues; recruitment, selection and socialization; the use of social media at work; and the interactive service sector. He has published in world leading international journals including Human Relations, Journal of Service Research and Human Resource Management Journal. His work has been featured on the LSE Business Review and British Politics and Policy blogs, and on The Conversation. He is also on the Editorial Board of Employee Relations. 